\title{
Post-vaccinial pericarditis and myocarditis
}

\author{
A. W. Matthews and I. D. Griffiths \\ From the Department of Medicine, Southampton General Hospital
}

$A$ case is described of pericarditis and myocarditis with severe cardiac failure, occurring two weeks after primary smallpox vaccination. Treatment with corticosteroids, digoxin, and diuretics was followed by prompt resolution of the heart failure and subsequent complete recovery.

Cardiac complications of smallpox vaccination have been reported in a small number of cases but are much less common than neurological or dermatological reactions.

Cangemi reported a case of acute pericarditis occurring 16 days after primary vaccination in a 56-year-old man with apparent full recovery (Cangemi, 1958). During the 1962 smallpox outbreak, 3 cases of cardiac involvement after vaccination were reported (MacAdam and Whitaker, 1962). At the same time a fatal case of acute myocarditis was reported in the Times (Mant, 1962). Two other fatal cases have been described in English language journals (Dalgaard, 1957; Finlay-Jones, 1964).

We wish to describe a case of pericarditis and myocarditis with cardiac failure occurring two weeks after primary vaccination.

\section{Case report}

A 25-year-old motor mechanic was admitted to hospital I4 days after a primary smallpox vaccination. This had been followed by a vigorous local reaction, pyrexia, and general malaise.

Two days before admission he developed persistent severe central chest pain, aggravated by respiration and relieved by sitting forward. On examination his temperature was $38.9^{\circ} \mathrm{C}$, pulse 100 a minute regular, blood pressure $140 / 90 \mathrm{mmHg}$. The heart was not enlarged, the heart sounds were normal, there was no pericardial friction rub, and no signs of heart failure. On the left upper arm was a large ulcerated pustule with surrounding erythema and axillary lymphadenopathy. No other skin lesions were present and neurological examination was normal.

The initial investigations showed $\mathrm{Hb} \times 4.8 \mathrm{~g} / 100 \mathrm{ml}$, WBC $20,200 / \mathrm{mm}^{3}$ ( $83 \%$ polymorphs), ESR 35 rising to $86 \mathrm{~mm} /$ hour (Westergren) within 48 hours. The blood urea was $63 \mathrm{mg} / 100 \mathrm{ml}$, serum electrolytes normal. The electrocardiogram revealed changes of acute pericarditis
(Fig. I). The chest $x$-ray showed a normal heart size and clear lung fields. The serum aspartate aminotransferase level was I32 RF units/ml, serum bilirubin $2.2 \mathrm{mg} / 100 \mathrm{ml}$, serum alkaline phosphatase $7 \mathrm{KA}$ units/ roo ml, serum albumin $3.9 \mathrm{~g} / 100 \mathrm{ml}$, serum globulin

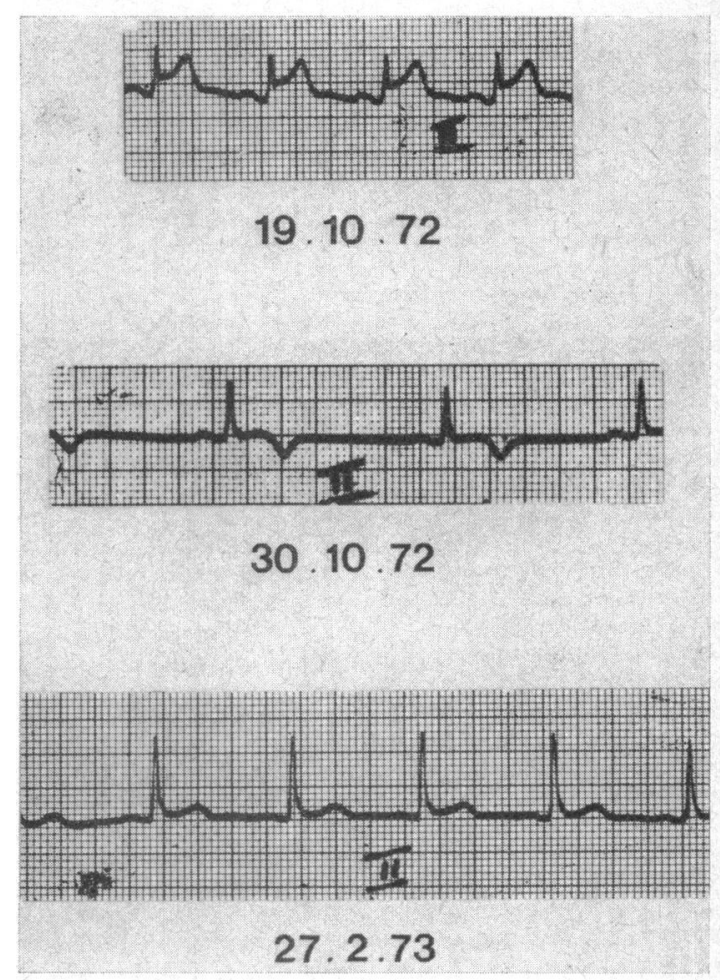

FIG. I Serial electrocardiograms (lead II) showing changes of acute pericarditis with progress and resolution. 
$3.2 \mathrm{~g} / 100 \mathrm{ml}$, with a relative increase of the alpha-2 fraction. Serum immunoglobulins were $\mathrm{IgG} 1700 \mathrm{mg} /$ $100 \mathrm{ml}$ (normal $800-1000$ ), IgA $380 \mathrm{mg} / 100 \mathrm{ml}$ (normal 140-420), IgM $280 \mathrm{mg} /$ I0Oml (normal 50-200). The antistreptolysin $\mathrm{O}$ titre, blood culture, Paul Bunnell, toxoplasma dye test, cytomegalovirus and other viral antibodies and cultures were all negative. The autoimmune profile was normal and the serum complement slightly raised at $190 \mathrm{mg} / \mathrm{I} 00 \mathrm{ml}$ (normal $80-180$ ).

His condition remained unchanged until the third day after admission when he developed cough, increasing dyspnoea and orthopnoea, tachycardia of 140 a minute, a gallop rhythm, raised jugular venous pressure, and bilateral crepitations. The chest $x$-ray now showed considerable cardiac enlargement and pulmonary oedema (Fig. 2).

He was treated with digoxin and frusemide, and in view of a possible immunological basis for his myocarditis he was given hydrocortisone $200 \mathrm{mg}$ intravenously followed by prednisone $60 \mathrm{mg}$ daily. Within 12 hours there was a dramatic improvement with complete resolution of the pulmonary oedema and return of the temperature and pulse rate to normal (Fig. 3).

Subsequently he made an uneventful recovery. Digoxin and diuretics were withdrawn after 5 days but prednisone was continued in reducing doses for 4 weeks. The chest $x$-ray showed resolution of the cardiac enlargement in 5 days. The electrocardiogram, however, developed widespread $T$ wave inversion but returned to normal 3 months later (Fig. I).

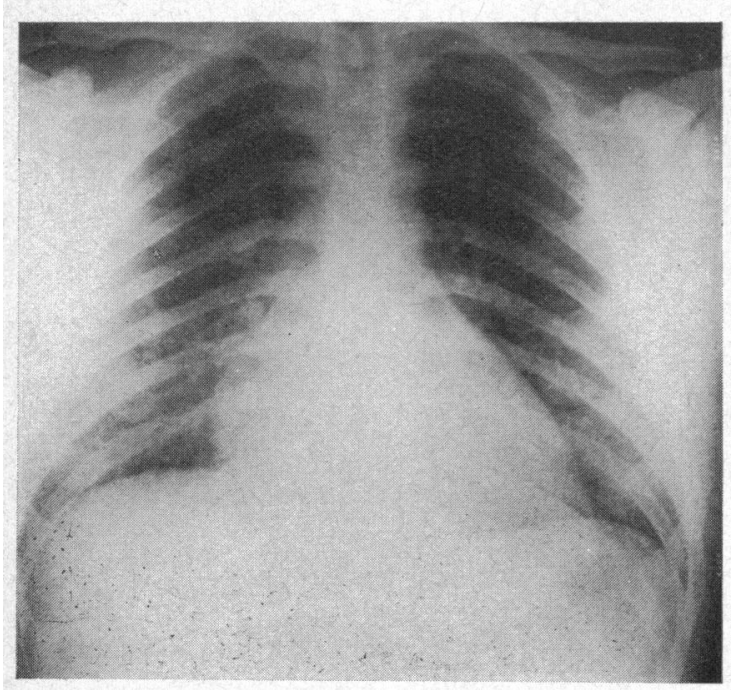

FIG. 2 Chest $x$-ray (20.10.72) showing cardiac enlargement and pulmonary oedema.

\section{Discussion}

Although symptomatic cardiac complications after smallpox vaccination are rare it is possible that subclinical manifestations occur more frequently. A study during the Stockholm outbreak in 1963 revealed electrocardiographic abnormalities compatible with pericarditis or myocarditis in 192 patients admitted to hospital with other postvaccinial complications (Bengtsson, Holmgren, and Nyström, 1966). At the same time an electrocardiographic survey before and after vaccination in $\mathbf{2 8 6}$ military personnel showed abnormalities compatible with myocarditis in 3 cases (Ahlborg, Linroth, and Nordgren, 1966).

These post-vaccinial reactions could be the result of either direct viral invasion or hypersensitivity to the virus or calf lymph. The described cases have usually occurred 1o to 14 days after a primary vaccination. This time course suggests an allergic mechanism, possibly due to formation of immune complexes. In addition, no case has been associated with generalized vaccinia though severe local reactions appear to be a constant feature. In our patient, though he was given digoxin and diuretics, the response to treatment with corticosteroids was so dramatic that it seems probable that these had some effect on the underlying process.

We would like to thank Professor J. B. L. Howell for his advice and permission to publish this case.

\section{References}

Ahlborg, B., Linroth, K., and Nordgren, B. (I966). E.C.G. changes without subjective symptoms after smallpox vaccination of military personnel. Acta Medica Scandinavica, Suppl. 464,127 .

Bengtsson, E., Holmgren, A., and Nyström, B. (1966). Circulatory studies in patients with abnormal E.C.G. in the course of post-vaccinal complications. Acta Medica Scandinavica, suppl. 464, II3.

Cangemi, V. F. (1958). Acute pericarditis after smallpox vaccination. New England fournal of Medicine, 258, 1257.

Dalgaard, J. B. (1957). Fatal myocarditis following smallpox vaccination. American Heart fournal, 54, 156.

Finlay-Jones, L. R. (1964). Fatal myocarditis after vaccination against smallpox. New England fournal of Medicine, 270, 4I.

MacAdam, D. B., and Whitaker, W. (1962). Cardiac complications after vaccination for smallpox. British Medical fournal, 2, 1099.

Mant, A. K. (1962). Fatal reaction to vaccination. The Times (London), 22 February 1962.

Requests for reprints to Dr. A. W. Matthews, Department of Medicine, Southampton General Hospital, Oakley Road, Southampton SO9 4WQ. 


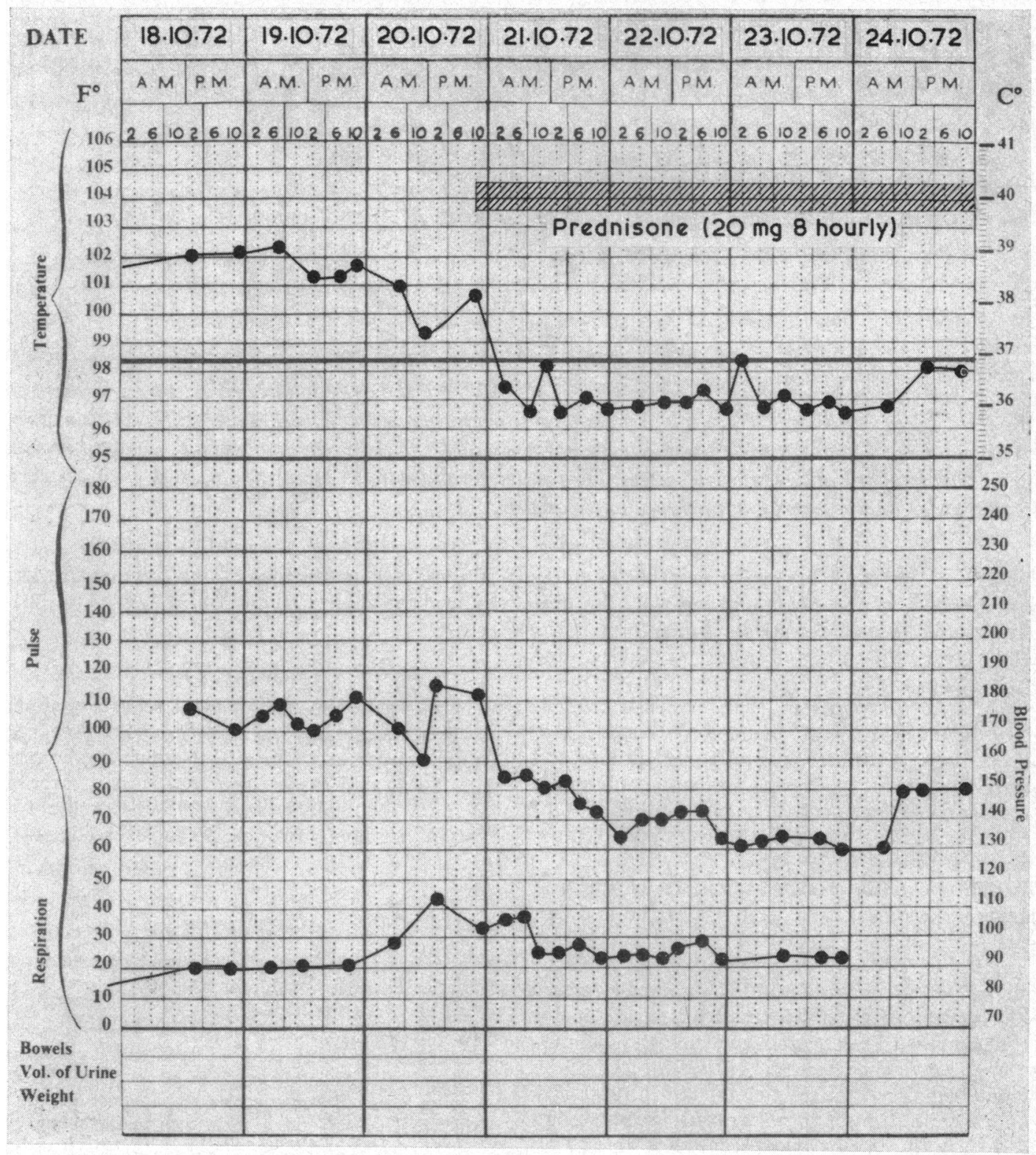

FIG. 3 Temperature chart showing resolution of pyrexia and tachycardia after treatment. 